\title{
The Kyoto Protocol after Marrakesh
}

\author{
C Dasgupta
}

Distinguished Fellow, TERI, Darbari Seth Block, Habitat Place, Lodhi Road, New Delhi - 110 003, India

International Journal of Regulation and Governance 2(1): 45-52

\begin{abstract}
The accords reached at Bonn and Marrakesh resolved important operational questions left open at Kyoto and gave final shape to the Kyoto Protocol. This achievement came at a considerable price in terms of defining the Kyoto targets as well as procedural transparency.

The accords have drained 'supplementarity' of all operational significance. It imposes no ceiling on the extent to which an Annex I Party may take recourse to the 'flexibility mechanisms'. Thus over $50 \%$ of the notional reduction in emissions is likely to be accounted for by trading in 'hot air'-a mere accounting device. This figure could be even larger unless steps are taken to ensure that the entry of Kazakhstan (and any other country) into Annex I for the purposes of the protocol does not lead to a further expansion in the supply of 'hot air'.

The agreed ceilings for additions to and subtractions from the assigned amounts of Parties for forest management activities will enable the Annex I Parties to account for another 38.31\% of their notional emission reduction commitments. There was a certain lack of transparency in the manner in which the ceilings were calculated.

Thus the actual reduction in emissions required of the Annex I Parties will be very modest-just over $11 \%$ of the notional figure. This includes credits for joint implementation and clean development mechanism projects besides domestic actions. Only a very small part of the Kyoto targets is likely to be met through domestic actions in Annex I countries. The Kyoto Protocol, as given final shape in Marrakesh, will at best lead to a marginal reduction in the actual GHG emissions of ratifying Annex I countries.
\end{abstract}


When the Kyoto Protocol was adopted in December 1997, it was widely hailed as a breakthrough in international regulation and governance of the atmosphere. The operational details left for further negotiation were not viewed as a major problem; yet it took nearly four years of further negotiations in The Hague, Bonn, and finally, Marrakesh to resolve these outstanding differences. This suggests that the questions finally resolved through the Marrakesh Accords (adopted at COP-7 in OctoberNovember 2001) were not simply matters of detail but issues of substantive importance.

The initial lack of progress in resolving the outstanding operational questions at COP-6 in The Hague and the decision of the Bush administration to disregard the Kyoto accord gave rise to some pessimism about the future of the Protocol. It was far from clear whether the Protocol would come into operation. Entry into force requires accession by at least 55 countries, including Annex I Parties accounting for at least 55\% of the total carbon dioxide emissions for 1990 of the Parties included in Annex I. Since the US alone accounted for $36.1 \%$ of these emissions, entry into force requires accession not only by the EU countries (24.1\%) but also Russia (17.4\%), and for all practical purposes, Japan $(8.5 \%)$, apart from others to make up for the balance. The failure at The Hague to resolve differences between the EU on the one hand and Russia and Japan on the other gave rise to fears that the Kyoto Protocol might prove still-born. Moreover, it was doubted if a multilateral agreement with major economic implications could be implemented in the absence of the US.

The successful conclusion of negotiations in Marrakesh has cleared the way for accession by the principal Annex I Parties. There is thus reason to hope that the Kyoto Protocol will enter into force by early next year. This achievement has, however, come at a considerable price in terms of the Kyoto targets as well as the transparency and scientific integrity of Protocol procedures. Vigilance is required to ensure that Marrakesh turns out to be more than a Pyrrhic victory.

\section{Target dilution - 'hot air'}

It is widely recognized that a weak feature of the Kyoto Protocol is its provision for emissions trading between Annex I Parties (Article 17, read together with Annex B). In a number of EITs ('economies in transition' from central planning to free markets), GHG (greenhouse gas) emissions have shown a significant 
reduction because of a sharp decline in the level of economic activity. Between 1990 and 1998, GHG emissions from the EIT countries registered a decline of $37.2 \% .^{1}$ The 'assigned amounts' for these countries were fixed on the basis of very generous assumptions concerning the speed of economic recovery and 'business as usual' scenarios, with the result that it has become possible for many of these countries to sell their surplus allocation without having to carry out any planned emissions reduction. This trade in 'hot air' amounts to a mere accounting transaction that transfers emissions from one Annex I Party to another, without reflecting any planned reduction of emissions.

The Marrakesh Accords could well result in expanding the trade in 'hot air' in two ways: firstly, its interpretation of 'supplementarity' and secondly, the induction of Kazakhstan into Annex I for the purposes of the Kyoto Protocol.

\section{Supplementarity}

The Kyoto Protocol recognized that Annex I Parties should achieve their respective emissions reduction commitments primarily through domestic measures, rather than through recourse to the 'flexibility mechanisms'. Thus, Articles 6 and 17, dealing with joint implementation and emissions trading, respectively, stipulate that these measures 'shall be supplemental to domestic actions for the purposes of meeting commitments.' (Even though Article 12, concerning the CDM (clean development mechanism), carries no such restriction, negotiators at COP6 and COP-7 extended the application of the 'supplementarity' condition to all the three flexibility mechanisms.) The Kyoto Protocol did not define the extent of the restriction implied by the term 'supplemental'; no specific ceiling was imposed on recourse to the flexibility mechanisms. It was left to future negotiations to resolve this question.

At COP-6 and 6.5, attempts were made to define 'supplementarity' by placing a ceiling on the extent to which an Annex I Party could meet its commitment through the flexibility mechanisms. The ceiling was to be expressed as a percentage of its total commitment and was intended to ensure that the greater part of the commitment would be met through domestic action. Thus, at one stage, one of the options proposed was a

\footnotetext{
1 Document no. FCCC/SBI/2000/11. This document can be accessed at $<$ www.unfccc.int/ $>$.
} 
ceiling of $30 \%$ for recourse to the 'flexibility instruments'. ${ }^{2}$ These attempts had to be given up in the face of determined opposition by the 'umbrella group'. The Marrakesh Accords define 'supplementarity' as simply requiring that 'domestic action shall...constitute a significant element' of the effort made by each Annex I Party to meet its commitment. This makes the concept quite meaningless in terms of restricting recourse to "hot air' trade (or to other flexibility mechanisms). The Marrakesh formulation is open to the interpretation that domestic measures might constitute the smaller part of the effor ts of Annex I Parties. Any hope that the 'supplementarity' requirement might significantly limit recourse to 'hot air' was extinguished in Bonn and Marrakesh.

\section{Kazakhstan - more 'hot air'?}

Kazakhstan's entry into Annex I at COP-7 brought into focus an anomaly in the Kyoto Protocol. It may be recalled that the question of allowing a non-Annex I country to join Annex I through voluntary adoption of a quantified commitment was considered in Kyoto. A proposal to this effect was at one stage set out in Article 10 (later Article 9) of the Kyoto draft document. The draft article had to be dropped from the final text as it was unacceptable to a large number of developing countries (Grubb, Vrolijk, and Brack 1999 p.110). What was thrown out through the front door was, however, brought back through the back door. Article I, which set out definitions, lays down that 'Party included in Annex I' means 'a Party included in Annex I to the Convention, as may be amended, or a Party which has made a notification under Article 4, paragraph 2 (g), of the Convention' (emphasis added). Thus, the term 'Annex I Party' was so defined as to achieve the same object as the proposal which had to be dropped because it was opposed by most developing countries! The anomaly was compounded by the fact that the Kyoto Protocol contains no 'Annex I'; yet an 'Annex I Party' under the Protocol need not figure in Annex I of the parent Convention. Kazakhstan has become the first country to be treated as an 'Annex I Party' for the purposes of the Protocol, while remaining a non-Annex I country in terms of the Convention.

Kazakhstan's carbon emissions have fallen sharply in the last decade owing to economic dislocation. Its carbon dioxide

2 Document no. FCCC/CP/2000/CRP.3. This document can be accessed at $<$ www.unfccc.int $/>$.

International Journal of Regulation and Governance 2(1): 45-52 
emissions from fuel combustion fell from 215.94 MT (million tonnes) in 1993 to $126.24 \mathrm{MT}$ in 1998 (International Energy Agency 2000). Thus, its entry into Annex I (for the Protocol) could open up the possibility of a further substantial increase in the supply of 'hot air' if 'business as usual' projections reflect excessively optimistic assumptions regarding economic recovery and growth. The problem could be further compounded if other members of the CAC\&M (Central Asia, Caucasus, and Moldova) group decide to follow Kazakhstan into Annex I. (Though these countries have not so far indicated a desire for Annex I status, they have described themselves as 'economies in transition', a sub-category within Annex I. ${ }^{3}$ There is a very real possibility that the Kyoto Protocol will become totally meaningless unless the doors are firmly closed against any further increase in the supply of 'hot air'.

In order to prevent a further expansion of 'hot air' it is essential that any QELRO (quantified emission limitations and reduction obligations) assigned to Kazakhstan (and any future Annex I entrant) should ensure that it is required to carry out meaningful, planned emission reductions. Its quantitative commitment would have to be significantly lower than its projected emissions for 2008-12. Emission projections should reflect observed trends and not simply optimistic assumptions about economic revival and growth. If a reliable statistical base is not available for calculating Kazakhstan's base year, current or projected emissions, assignment of a QELRO should be deferred until the next commitment period.

\section{Scientific integrity/transparency}

At COP-6.5, agreement was reached on ceilings for additions to and subtractions from the assigned amounts of parties resulting from forest management activities undertaken in the first commitment period. There was a certain lack of transparency regarding the calculations. The Marrakesh document explains in a footnote that 'a combination of data provided by Parties and by the FAO (Food and Agriculture Organization) was used. It is not clarified whether a careful examination was undertaken to establish whether the FAO data met the requirements of the Protocol. The footnote goes on to state that "consideration was also given to national circumstances (including the degree of effort

3 Document no. FCCC/CP/2001/12 (11 October 2001). This document can be accessed at <www.unfccc.int $/>$.

International Journal of Regulation and Governance 2(1): 45-52 
needed to meet Kyoto commitments and the forest management measures implemented)'. This seems to suggest that a certain political element entered the calculations. Misgivings about the scientific integrity of the calculations were compounded when, in Marrakesh, the ceiling for Russia was almost doubled - from $17.63 \mathrm{MTC} /$ year (million tonnes of carbon per year) to 34 MTC/year - without any public clarification about the basis of calculation beyond the bland statement that an 'error' had been corrected. The lack of transparency deepened the conviction that the ceilings were dictated by the political compulsions of bringing Russia and the 'umbrella group' countries on board.

\section{Implications for the Kyoto targets}

What are the implications of the Marrakesh Accords in terms of the emission reduction targets of the Kyoto Protocol? More specifically, what are the implications of the trade in 'hot air' and the ceilings on forest management credits?

It is obviously difficult to accurately estimate the size of the 'hot air' problem. According to one authority, 'depending partly upon trends in Russia and Ukraine, it could amount to several hundred million tonnes of carbon-equivalent - perhaps as much as $10 \%$ of total Annex I allowed emissions' (Grubb, Vrolijk, and Brack 1999 pp. 213-214). Since this is almost double the size of the reduction required by the Kyoto Protocol, it would seem that the dimensions of the loophole could be so large as to altogether negate the objective of the Protocol.

A more modest estimate is offered in a recent Asian Development Bank study based on national communications submitted to the FCCC Secretariat (Halsnaes 2000). This estimates that the tradeable surplus in the EITs would amount to 92.4 MTC/year, whereas the reductions required by the Kyoto Protocol (from business-as-usual levels) would amount to a total of $184 \mathrm{MTC} /$ year for the Annex I Parties, excluding the US. After interpolating the forestry ceilings agreed at Marrakesh, the picture that emerges from this scenario is set out in Figure 1. It shows how the Annex I Parties, excluding the US, are likely to meet their overall emissions reduction targets.

It will be seen that, even in this scenario, $50.22 \%$ of the overall target is likely to be accounted for by 'hot air' trade-that is, a mere transfer of emissions from one Annex I Party to another, without any real reduction of emissions. (This share would be even larger if Kazakhstan or other new entrants into Annex I, are 


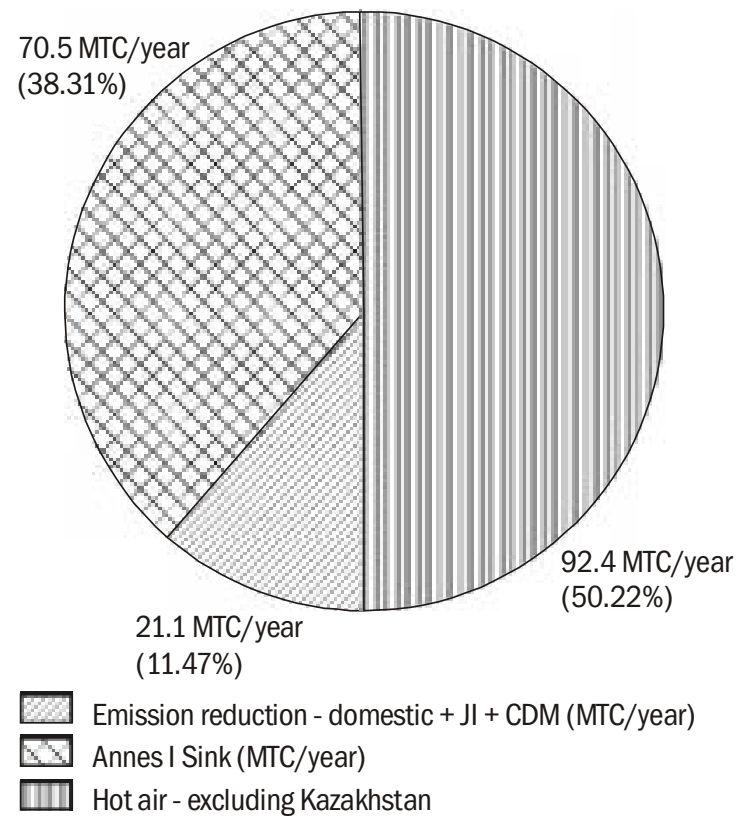

Figure 1 How Kyoto targets might be met?

permitted to bring new supplies of 'hot air' to the market.) Another $38.31 \%$ would be accounted for by forestry management activities in Annex I countries, assuming that the cheap options offered here are fully exploited. The balance $11.47 \%$ would be achieved through emission reductions achieved through domestic actions plus joint implementation and CDM projects.

In other words, even if we avoid the most pessimistic scenarios,

1 the notional reduction in emissions of Annex I Parties to the Kyoto Protocol is likely to be quite modest-184 MTC/year ;

2 half or even more of this figure will be covered by an accounting exercise involving 'hot air';

3 the actual reduction in emissions will be a small part-a little over $11 \%$ of the notional net reduction; and

4 domestic actions in Annex I countries will account for a very small part of the overall reduction. The Marrakesh Accords make this possible because they have made 'supplementarity' a meaningless requirement.

The Kyoto Protocol, as given final shape in Marrakesh, is likely at best to lead to a marginal reduction in the GHG 
emissions of the Annex I Parties (excluding the US). Even this marginal benefit may be lost unless adequate care is taken to avoid a further inflation of 'hot air' and unless rigorous scientific accounting is applied to sinks.

\section{References}

Grubb M, Vrolijk C, and Brack D. 1999

\section{The Kyoto Protocol}

London: Royal Institute of International Affairs

Halsnaes K. 2000

Estimation of the global market potential for cooperative implementation mechanisms under the Kyoto Protocol

In Implementation of the Kyoto Protocol, edited by P Ghosh

Manila: Asian Development Bank

International Energy Agency. 2000

$\mathrm{CO}_{2}$ Emissions from Fuel Combustion: 1971-1998 (P.II. 273)

Paris: International Energy Agency 